REGULAR ARTICLE

\title{
INTERMEDIARIES AND ASYMMETRIC PRICING: EVIDENCE FROM THE MARKET OF LOCAL MILLET IN MALI
}

\author{
Alou DEMBELE ${ }^{*}$, Ahmet ÖZÇELIK $^{1}$, Ernest OUEDRAOGO ${ }^{2}$, Lamissa DIAKITE $^{3}$
}

\author{
Address: \\ ${ }^{1}$ Ankara University, Department of Agricultural Economics, Ankara, Turkey \\ ${ }^{2}$ University of Ougadougou, Department of Economics, Burkina Faso \\ ${ }^{3}$ Agro-économiste, Maître de Recherche, Président Directeur Général (PDG) Agence d'Aménagement des Terres et de \\ Fourniture de l'Eau d'Irrigation (ATI), Mali \\ * Corresponding author's e-mail: alou.dem10@gmail.com; dembele@ankara.edu.tr
}

\begin{abstract}
Commodity prices consistently increase in developing countries while they barely decline, affecting negatively poor and vulnerable people. This paper examines the role of intermediaries such as collectors, wholesalers, and retailers in the asymmetric trans mission of millet prices from producers to consumers in local millet markets in Mali. We use data of local millet prices from the five most important cities in terms of local millet production in Mali namely; Bamako, Segou, Kayes, Koulikoro and Sikasso. Using the Threshold Auto-Regressive (TAR) method developed by Enders and Siklos (2001), at the exogenous threshold, we found an asymmetrical transmission between Koulikoro and Ségou collectors' market. The result shows that, collectors in Koulikoro promptly transmit price increases while they lately transmit price decline at exogenous threshold. Strong evidence was found to suggest that, collectors in Koulikoro and wholesalers in Sikasso punctually transmit a decrease in millet prices to consumers while they tardily transmit the increase in prices to consumers even though the effect of prices increment are relatively larger than the effect of price decrease at endogenous threshold. By applying a zero exogenous threshold we found a non-asymmetric cointegration between Kayes and Ségou, Sikasso and Ségou 'collectors market and between Sikasso and Ségou wholesalers' market. Regardless of the threshold chosen in retailers market, we found symmetric prices transmissions between all the markets pairs. In order to reduce this asymmetric price transmission and to fight against poverty, the authors suggest that decision-makers should consider introducing millet price control in the local markets, especially when millet prices increase spontaneously.
\end{abstract}

Keywords: Asymmetric price control, Intermediaries, Local millet, Mali, Price transmission JEL: R52, R58, H41

\section{INTRODUCTION}

Despite the important strides and initiatives for poverty reduction by the Millennium Development Goals (MDGs) over the last decades, Mali remains one of the poorest countries in the world with more than 50 percent of its population are living below US\$1.25 per day and more than $10.7 \%$ of children are still suffering from hunger and malnutrition (INSAT, 2017). One of the explanations of this level of poverty, hunger and malnutrition is the fast rise in commodity prices due to the impact of climate changes, which affects agricultural product. The average price of cereals such as millet has risen more than 21 percent between 1990 and 2010 (Diarra et al., 2011). Only within the period 2011-2012, the price of millet increased by 67 present (Diarra et al., 2011). The same figure is observed in other developing countries where consumer price level of commodities had risen faster than it is falls, which led to the nutrition crisis in the country. For example, in Burkina Faso, the average price of cereal increased by 4\% from 2011 to 2012 (MASSA, 2013). This asymmetric increase in commodity prices mainly affects poor and vulnerable people such as children and women, and that may restrain development goals and achievement in terms of poverty reduction.

Taking into consideration the context of UN Sustainable Development Goals (SDGs) which make a development case for reducing poverty and undernutrition in developing countries, this increase in commodity prices becomes problematic. One major explanation for this persistent increase in commodity prices is the presence of a large number of intermediaries between the producers and the consumer (Diarra, 2008). In the developing or middle-income countries, or that will affect worldwide food security and leads to the famine (Şahinli and Fidan, 2011). Actually, intermediaries play a central role in the millet market in Mali by engaging in the collection, distribution, import and export of the cereal products between local, regional and international markets. Through these activities, they take advantage of the lack of producer's organization in the cereals markets to influence prices for their benefit.

From literature point of views, many scholars have addressed the issues of price transmission in developing countries, focusing on the transaction cost from international market to local market (Diarra, 2008), the role of tax policies (Meuriot, 2012), as well as the temporal and spatial inefficiency of the cereal markets 
(Diakité, 2006). On the role of intermediaries in the asymmetric transmission, Meyer and Von CramonTaubadel (2004) finds that the market power of intermediaries leads to price asymmetric transmission. Authors such as Kinnucan and Forker (1987) have studied the asymmetric price responses applied to commercial value chains, which relate to vertical integration, particularly the relations between operators, retail trade and wholesale trade. They then showed that the price responses are asymmetric, knowing that for retail prices, price increments are reflected faster than its decrease. (McCorriston et al., 2001; Carman and Sexton, 2005; Lloyd et al., 2006) develop empirically the relationship between the market power of intermediaries and the transmission of prices. Moreover, they show that the persistence of asymmetry in price transmission is not only due to the strength of the market only, but is also due to others factors such as lack of market information, the presence of transaction costs, and the degree of risk. Abdulai (2000) tested the existence of asymmetry transmission of maize's price in Ghana. His results show that the presence of dealer networks, retailers, semiwholesalers and larger wholesalers with a large market power induce asymmetric transmission of maize's prices in Ghana. In developed countries as well, studies also found that the market power of intermediaries is one of the most important factors of price transmission (Miller and Hayenga, 2001; Lass, 2005; and Llyod et al., 2006). Şahinli and Fidan (2010) also studied the profit level and price formation in hazelnut production in Turkey and they found the presence of intermediaries is motivated by the profit level in the market. Some years prices received by producer is higher than other is. They show that in some years, prices increase and in some years price decrease in the product market. This variability is probably due to the market imperfection such as the presence of intermediaries who try to increase their profit level. Abbassi et al. (2012) addressed the issue of the impact of inventories on prices transmission in the Canadian chicken industry and found a strong correlation between sales and wholesalers prices.

In this paper, we address this issue by analysing the role of intermediaries in the asymmetric transmission of the price of local millet in Mali by taking into consideration the five most important cities in of millet production in the country. We focus on the role of collectors and wholesalers as the main intermediaries. We applied TAR method developed by Enders and Siklos (2001) to test the price transmission between the central market (Ségou) and the other markets as well as Kayes, Koulikoro and Sikasso and Bamako consumers' market. We distinguished the response to positive shocks and the response to negative shocks to identify the asymmetric transmission. We found strong evidence to suggest that, collectors in Koulikoro and wholesalers in Sikasso punctually transmit a decrease in millet prices to consumers while they tardily transmit the increase in prices to consumers at endogenous threshold. The results shows that, collectors in Koulikoro promptly transmit price increases while they lately transmit price decline at exogenous threshold.

\section{DATA AND METHODS}

\section{Data and Stationary Issues}

We used data on monthly prices collected over the period 1993-2013 by the OMA (Agricultural Market Observatory at Mali). The dataset contains information about producer prices, the collector's prices, the wholesale prices, and retail prices of millet in Mali. Our analysis focused on the five major regions of Mali, which are Kayes, Koulikoro, Sikasso, Ségou, and Bamako's retail prices of millet in Mali. The region of Ségou is the leading producer of local millet in Mali, while Bamako is more of a consumption region. Figure1 presents the circuit of millet's price transmission from producer's market to consumer's market through the intermediaries. Following this chain, a shock on the producer's price will be transmitted to consumers through the intermediaries.

A major threat to the identification of the role of intermediaries in the asymmetric transmission of price is the presence of non-stationarity nature in the prices series. To avoid the risk of inconsistency and fallacious regression, we first test for the stationarity of the price series. To test for stationarity, we rely on the Augmented Dickey and Fuller (ADF) unit root test, which is based on the null hypothesis of the presence of unit root (nonstationarity). The test is performed sequentially by comparing the value of the ADF statistic with the critical values tabulated by (Mackinnon, 1991). If the ADF statistic is greater than the critical values tabulated by Mackinnon (1991), we do not reject the null hypothesis of unit root presence, which implies that the series is nonstationary. We then differentiate the series and repeat the test until it is stationary. The results of the stationary test are present in Table 1. These results show that all our series are stationary at level. At this extent, we can analyse the cointegration between these prices.

\section{Identification Strategy}

Our empirical strategy uses the cointegration existing between the prices in millet markets to analyse the role of intermediaries in the asymmetric transmission analysis. We employ the TAR model developed by Enders and Siklos (2001). Eq. 1 gives the empirical specification.

$P_{i, t}=\Psi+\Psi_{1} P_{j, t}+\mu_{t}$

Where: $i=$ Kayes market or Koulikoro market or Sikasso market; $j=$ Ségou market;

$P_{i, t}$ is the millet's price in market $i$ at time $t$ and $P_{j, t}$ is the millet's price in market $j$ at the time $t . \Psi_{1}$ captures the transmission of the millet's price from the market $j$ to the market $i$.

We focus on price transmission from the market of Ségou, which is the largest producer region, to the other markets (Kayes, Koulikoro and Sikasso). A full price transmission implies $\psi 1=1$ and $\psi 1=0$ implies that the two markets are not related. Unlike Dickey-Fuller's standard cointegration test, the test of Enders and Siklos (2001) assumes that the speed of adjustment depends on the nature of the shock (positive and negative). This property allows us to test the transmission of positive and negative 
chocks in the local millet market (Eq. 2).

$\Delta \mu_{t}=I_{t} \rho_{1} \mu_{t-1}+\left(1-I_{t}\right) \rho_{2} \mu_{t-1}$

with $I_{t}=\left\{\begin{array}{l}1 \text { if } \mu_{t-1 \geq s} \\ 0 \text { if } \mu_{t-1<s}\end{array}\right.$

Where: $\Delta \mu_{t}$ Vis the variation of the error at time $\mathrm{t} ; I_{t}$ An indicator variable; $\vartheta_{t}$ the error term, $\mathbf{s}$ represents the value of the threshold.

Trust, $\rho_{1}$, and $\rho_{2}$ indicate the adjustment of negative and positive sequences in the model. To get a better specification of the model, we add the time-lag values of $\Delta \mu_{t}$ to allow $\vartheta_{t}$ being a white noise. The criterion for selecting the number of lags is carried out from the Akaike Information Criterion (AIC) or Bayesian Information Criterion (BIC). The number of lags selected is the one that minimizes these criteria. The model is written as Eq.3.

$\Delta \mu_{t}=I_{t} \rho_{1} \mu_{t-1}+\left(1-I_{t}\right) \rho_{2} \mu_{t-1}+$

$\rho_{3} \Delta \mu_{t-2} \ldots \ldots . \rho_{p} \Delta \mu_{t-p}+\vartheta_{t}$

\section{Estimation method}

There are two-steps involved to estimate the TAR model. First, the case of null threshold and the case of the unknown threshold. The estimation of the model of Enders and Siklos (2001) requires first to estimate the long-term relationship and to collect the residuals resulting from this estimation.

In order to test the validity of TAR, two statistics are used, namely the statistic related to the null hypothesis $\rho_{1}=0$ or $\rho_{2}=0$ and the statistic $\varnothing$ of the joint hypothesis $\rho_{1}=\rho_{2}=0$. Indeed, the largest statistic is called t-max and the one with the smallest value is call tmin.

The t-max makes it possible to test that $\rho_{1}=0$ and $\rho_{2}=0$ are significantly negative and the statistic $\emptyset$ makes it possible to test the hypothesis according to which $\rho_{1}=$ 0 and $\rho_{2}$ are jointly different from zero.

Thus, the null hypothesis of the TAR model is noncointegration. Cointegration occurs when the calculated t$\max$ value is lower than its value read on the table of Enders and Siklos (2001). For statistics, $\emptyset$ cointegration occurs when the calculated statistic is greater than its value read on the table of Enders and Siklos (2001). The statistic $\varnothing$ is more relevant than the $\mathrm{t}$-max statistic in the case where all the $\rho_{i}$ are negative and it has a higher power than the t-max.

The threshold, $\mathbf{s}$ is generally unknown and can be determined endogenously. The procedure involves estimating the long-term relationship and recovering the residuals from this estimate. In order to avoid the influence of the initial values, $15 \%$ of the first residues and $15 \%$ of the last residues are eliminated. The search for the potential threshold is done in the $70 \%$ of the remaining residues. For each potential threshold, the long-term relationship is estimated and the sum of the squares of the residues are retained. The threshold that minimizes the sum of the squares of the residues is the optimal threshold.

\section{RESULTS AND DISCUSSION}

\section{The Role of Collectors in Price Transmission}

Following a change in the millet "producer's price" at Ségou, Table 2 presents the price transmission to the "collectors' price" in the markets of Sikasso, Koulikoro, Kayes and Bamako. We consider an exogenous zero threshold. These results indicate that the speed of adjustment depends on the positive and negative nature of shocks. Indeed, $\rho_{i}$ with $\mathrm{i}=1,2$ are all negative and significant across all market pairs. These results indicate a convergent model. According to statistic, the adjustment of the negative shocks is equal to the adjustment of the positive shocks on Kayes-Ségou and Sikasso-Ségou market. There is a symmetrical cointegration relationship between these market pairs with a null threshold. In this threshold, the effects of positive shocks are transmitted in the same proportion as negative shocks. This means that, when a negative shock increases producer prices in Ségou such that the prices on the Sikasso and Kayes collection markets are above their long-run equilibrium levels; Sikasso, Kayes' market will transmit this price increase in the same proportion as it was a price decrease. There is an asymmetrical transmission for Koulikoro-Ségou relationship at exogenous threshold. The negative shocks are more quickly than positive shocks. At the endogenous threshold, there is the existence of a threshold effect only for the Koulikoro-Ségou relationship where the $\rho_{i}(\mathrm{i}=1.2)$ are all negative and significant at the $5 \%$ threshold. The negative sign reflects the convergence of the estimated models. Therefore, the positive shocks are more quickly than the speed of thenegative shocks. This concludes that the transmission effects of the shocks of the Ségou market to the Koulikoro market are characterized by an asymmetric adjustment with a threshold of null and -4.25 .

\section{The Role of Wholesalers}

Stemming from the previous results, the results in Table 3 suggest that wholesaler's adjustment to negative shocks is transmit in the same order as the adjustment to positive shocks on all market pairs at the exogenous threshold. In addition, we observed symmetrical cointegration between all pairs market except for Sikasso-Segou relationship. According to statistics, there is an endogenous threshold effect for the market pairs Sikasso-Ségou. There is also a convergent pattern between the models estimated for these relations ( $\rho_{i}$ are negative and significant). Thus, the responses to positive shocks are more important for the market pairs of Ségou. We observed that wholesalers react more quickly to lower prices than to higher prices. The intermediaries influence the transmission of prices by preventing a return to equilibrium after a positive shock.This leads us to admit that the market price transmission effects from Segou to the Sikasso wholesaler' markets are characterized by an asymmetric adjustment with a threshold of -2.24 . 


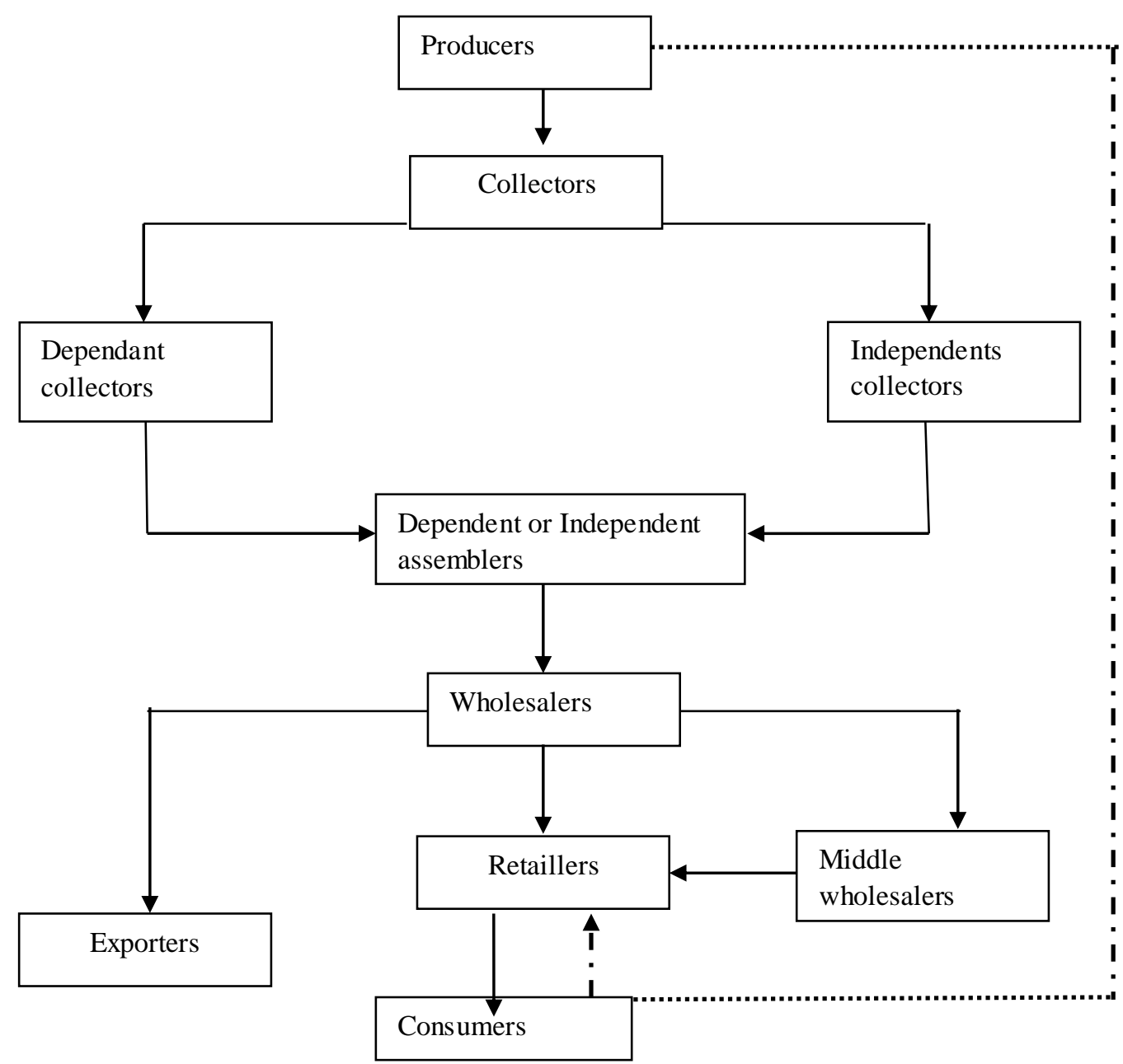

Figure 1: Circuit of price transmission in the millet's market

Table 1: Stationarity Test for Price Series

\begin{tabular}{llrrr}
\hline Regions & Variables & Level & Critical value & Conclusion \\
& & \multicolumn{3}{c}{ 5\% } \\
\hline Bamako & RPB & -4.092 & -3.430 & $\mathrm{I}(0)$ \\
Kayes & PPKa & -3.858 & -3.431 & $\mathrm{I}(0)$ \\
& CPKa & -3.026 & -2.880 & $\mathrm{I}(0)$ \\
& WPKa & -4.153 & -3.4 & $\mathrm{I}(0)$ \\
Koulikoro & PPKo & -5.247 & -3.430 & $\mathrm{I}(0)$ \\
& CPKo & -4.218 & -3.430 & $\mathrm{I}(0)$ \\
\multirow{5}{*}{ Sikasso } & WPKo & -4.042 & -3.430 & $\mathrm{I}(0)$ \\
& PPSi & -4.371 & -3.430 & $\mathrm{I}(0)$ \\
& CPSi & -4.181 & -3.4 & $\mathrm{I}(0)$ \\
Ségou & WPSi & -4.027 & -3.4 & $\mathrm{I}(0)$ \\
& PPSe & -4.326 & -3.430 & $\mathrm{I}(0)$ \\
& CPSe & -4.059 & -3.430 & $\mathrm{I}(0)$ \\
& WPSe & -4.027 & -3.430 & $\mathrm{I}(0)$ \\
\hline
\end{tabular}

Note: RPB is the retailer Price at Bamako market, PPK the producer price at Kayes market, CPK the collectors price at Kayes market, WPK is the wholesale price at Kayes market; PPSi is the producer price at Sikasso market, CPSi is the collectors price at Sikasso market, WPSi define the wholesale price at Sikasso market; PPSe define the producer price at Segou market, CPSe is the collectors price at Segou market; WPSe is the wholesale price at Segou market.

\section{The Role of Retailers}

The results of the estimation of the TAR model are summarized in the Table 4 . These results show the existence of price adjustment with a zero and endogenous threshold when the price changes are explained by Ségou's prices. It can be seen that the speeds of adjustment depend on the positive or negative nature of the shocks. There is then a convergent pattern between the models estimated when the threshold is zero because the $\rho_{i}$ of all the market pairs are significantly negative. On the other hand, the adjustment to negative shocks is equal to the adjustment to zero positive shocks. When the threshold is endogenous, 
only the Ségou production market converges to the Bamako's retail market. The reactions to negative shocks are as well equal to that of positive shocks. Positive shocks are also much more persistent that negative shocks. In addition, by referring to the statistic, we conclude there is a non-asymmetric cointegration at zero thresholds between the Bamako's retail market and the Ségou's collection as well as the wholesale and producer' market. Positive shocks are equal to negative shocks. That is, in the event of poor production in the Ségou area, leading to an increase in wholesaler and collection prices in Ségou such that the retail's price of Bamako is lower than its level of long-term production equilibrium. Then retailers (intermediaries) in Bamako will transmit this price increase to the retail's market in Bamako at the same speed that it is price decreasing. Therefore, as a result, our study should have taken all the regions. However, because of the limitation of data, we focused our analysis on the available data.

Table 2: The Role of Collectors in Price Transmission

\begin{tabular}{lrrrrrr}
\hline & CPKa- & CPKo- & CPSi- & CPKa- & CPKo- & CPSi- \\
& CPSe & CPSe & CPSe & CPSe & CPSe & CPSe \\
\hline$\rho_{1}$ & $-0.58^{*}$ & $-0.41^{* * *}$ & $-0.5^{* * *}$ & -0.09 & $-0.42^{* *}$ & -0.282 \\
& $(-1.79)$ & $(-3.21)$ & $(-5.29)$ & $(-1.34)$ & $(-2.47)$ & $(-1.34)$ \\
$\rho_{2}$ & $-0.72^{*}$ & $-0.44 * * *$ & $-0.58^{* * *}$ & -0.080 & $-0.21 * *$ & $-0.272^{* *}$ \\
& $(-1.69)$ & $(3.39)$ & $(-6.06)$ & $(-1.39)$ & $(-2.13)$ & $(-2.12)$ \\
$\rho_{1}=\rho_{2}$ & 0.48 & 0.09 & 1.14 & 0.12 & 2.09 & 0.00 \\
& $(0.48)$ & $(0.76)$ & $(0.29)$ & $(0.729)$ & $(0.15)$ & $(0.947)$ \\
$\emptyset$ & 1.10 & 6.39 & 16.48 & 0.75 & 3.27 & 1.53 \\
Threshold & $\mathrm{s}=0$ & $\mathrm{~s}=0$ & $\mathrm{~s}=0$ & $\mathrm{~s}=-1.41$ & $\mathrm{~s}=-4.25$ & $\mathrm{~s}=-2.68$
\end{tabular}

Notes: An asterisk $(*)$ denotes statistical significance at $10 \%$ level, $(* *)$ denotes statistical significance at the $5 \%$ level and $(* * *)$ denotes statistical significance at the $1 \%$ level. Values in parentheses are t-statistics.

The interpretation of the model is done using t-max statistics and $\emptyset$ tabulated by Enders and Siklos (2001), whose critical values for a sample of 250 are $-2.53,-2.12$ and-1.90 for the t-max statistic and 8.04, 5.87, and 4.92 for the $\emptyset$ statistic, respectively at the threshold $1 \%, 5 \%$ and $10 \%$.

Source: Authors computation based on OMA (2013) data.

Table 3: The Role of Wholesalers in Price Transmissioon

\begin{tabular}{lrrrrrr}
\hline \multicolumn{1}{c}{ WPKa- } & WPKo- & WPSi- & WPKa- & WPKo- & WPSi- \\
& WPSe & WPSe & WPSe & WPSe & WPSe & WPSe \\
\hline$\rho_{1}$ & $-0.30^{* * *}$ & $-0.16^{* *}$ & $-0.46^{* * *}$ & $-0.52^{* * *}$ & -0.11 & $-0.84 * * *$ \\
& $(-2.76)$ & $(-2.35)$ & $(-3.37)$ & $(-3.23)$ & $(-1.05)$ & $(-3.32)$ \\
$\rho_{2}$ & $-0.31^{* * *}$ & $-0.25^{* * *}$ & $-0.59 * * *$ & $-0.35 * * *$ & $-0.32 * *$ & $-0.63 * * *$ \\
& $(-3.14)$ & $(-2.82)$ & $(-3.81)$ & $(-2.99)$ & $(-2.32)$ & $(-3.22)$ \\
$\rho_{1}=\rho_{2}$ & 0.05 & 2.37 & $3.97 * *$ & 2.69 & $6.06 * *$ & $3.12^{*}$ \\
& $(0.82)$ & $(0.13)$ & $(0.05)$ & $(0.102)$ & $(0.02)$ & $(0.08)$ \\
& 3.32 & 3.48 & 6.61 & 4.85 & 2.32 & 3.87 \\
Threshold & $\mathrm{s}=0$ & $\mathrm{~s}=0$ & $\mathrm{~s}=0$ & $\mathrm{~s}=-4.38$ & $\mathrm{~s}=5.88$ & $\mathrm{~s}=-2.24$
\end{tabular}

Notes: An asterisk (*) denotes statistical significance at $10 \%$ level, $(* *)$ denotes statistical significance at the $5 \%$ level and $(* * *)$ denotes statistical significance at the $1 \%$ level. Values in parentheses are t-statistics.

Source: compute by authors, OMA (2013).

Table 4: The Role of Retailers in Price Transmission

\begin{tabular}{lrrrrrr}
\hline & RPB- & RPB- & RPB- & RPB- & RPB- & RPB- \\
& PPSe & CPSe & WPSse & PPSe & CPSe & WPSe \\
\hline$\rho_{1}$ & $-0.25 * * *$ & $-0.31 * * *$ & $-0.33 * * *$ & $-0.34 * *$ & -0.44 & -0.22 \\
& $(-3.15)$ & $(-3.79)$ & $(-4.11)$ & $(-1.80)$ & $(-1.51)$ & $(-1.31)$ \\
$\rho_{2}$ & $-0.32 * * *$ & $-0.39 * * *$ & $-0.44 * * *$ & $-0.34 * * *$ & $-0.241^{*}$ & $-0.38^{* * *}$ \\
& $(-3.39)$ & $(-3.94)$ & $(-4.07)$ & $(-2.58)$ & $(-1.78)$ & $(-1.97)$ \\
$\rho_{1}=\rho_{2}$ & 1.57 & 1.72 & 2.57 & 0.01 & 1.05 & $2.96 *$ \\
& $(0.21)$ & $(0.19)$ & $(0.11)$ & $(0.93)$ & $(0.31)$ & $(0.09)$ \\
$\emptyset$ & 4.86 & 8.21 & 7.38 & 2.29 & 1.32 & 1.55 \\
Threshold & $\mathrm{s}=0$ & $\mathrm{~s}=0$ & $\mathrm{~s}=0$ & $\mathrm{~s}=-5.21$ & $\mathrm{~s}=-5.88$ & $\mathrm{~s}=4.23$
\end{tabular}

Notes: An asterisk (*) denotes statistical significance at $10 \%$ level, $(* *)$ denotes statistical significance at the $5 \%$ level and $(* * *)$ denotes statistical significance at the $1 \%$ level. Values in parentheses are t-statistics.

Source: compute by authors, OMA (2013) data. 
Analysis of Commercial Margins on Local Millet Market As we argued above, intermediaries influence price transmission to increase their profits. In this section, we analyse the evolution of intermediaries' commercial margins. The commercial margin is the difference between the selling price and the purchase price that augmented the transaction cost of a good.

\section{Collector's Margins}

Figure 2 shows the evolution of the commercial margins of collectors. Despite a saw tooth evolution of prices, the aggregate collector margin of collectors remains stationary and positive according the Figure 2. Thus, we noted that, between 1993 and 1998, the collectors of Kayes earned an average commercial margin of 31 FCFA per kilogram. Between the periods of 1999 to 2005, the highest collector margin was recorded in the Koulikoro region (35 FCFA per kilogram). In the graph MCSE, MCSI, MCK and MCKO as define as the collectors' margin obtained at Ségou, Sikasso, Kayes and Koulikoro.

\section{Wholesaler's Margins}

Figure 3 shows a slight variability of commercial margins of wholesalers in the regions of Ségou, Sikasso, and Koulikoro. Moreover, apart from 1998/2002 and 2003/2004 figures, the wholesalers of Kayes recorded the highest margin over the entire study period with a maximum of 80 FCFA / $\mathrm{kg}$ observed in 2005. In addition, the evolution of wholesalers' margins was characterized by hollows and peaks, but stayed stationary and positive.

\section{Retailer's Margin}

Figure 4 shows the evolution of the commercial margins of retailers. We observed a sawtooth variability of the margins of retailers in all regions, including the district of Bamako. It is much more accentuated in Bamako and sometimes in the region of Kayes. The results suggest a significant difference between the margins achieved by retailers in the district (54 FCFA / kg in 2013 and those in other regions, except for the region of Kayes). In summary, the analysis reveals that intermediaries captured a positive margin over this period 1998- 2013 in the local millet's market despite the food crisis. This margin may explain the asymmetric price transmission in the local millet's market of Mali.

\section{DISCUSSION}

The descriptive analysis shows that intermediaries influence the prices transmission by increasing their commercial margins. This creates asymmetric transmission on Koulikoro-Ségou and Sikasso-Ségou markets pairs. However, we will have had to extend our study to the others regions, but due to the availability of data over the entire period, we have confined ourselves to the five major regions selected.

The analysis of the local millet collection market in Mali shows the existence of a price adjustment with a zero exogenous threshold when the price variations in the Kayes and Sikasso collection market are explained by the Ségou collection market. This result indicates that the speed of adjustment depends on the positive and negative nature of the shocks. Indeed, $\rho_{i}$ with $i=1,2$ are all negative and significant across all market pairs. It means that the estimated models are convergent. So, they is an endogenous threshold when the price variation in Koulikoro is explain by Ségou market. In this threshold, the negative shocks are more quickly than positive shock.The t-max statistic of the market pair Kayes-Segou relationship was -1.69 and is greater than its critical value tabulated in Enders and Siklos (2001) at the $1 \%$ threshold, which is -2.53 . In this case, the hypothesis of asymmetrical cointegration between the Kayes collection market and the Ségou collection market is rejected and the null hypothesis of asymmetric non-cointegration is accepted. The $\emptyset$-statistic calculated for the same relationship was 1.10 . It is below its critical value at the 1\% threshold tabulated in Enders et Siklos (2001).

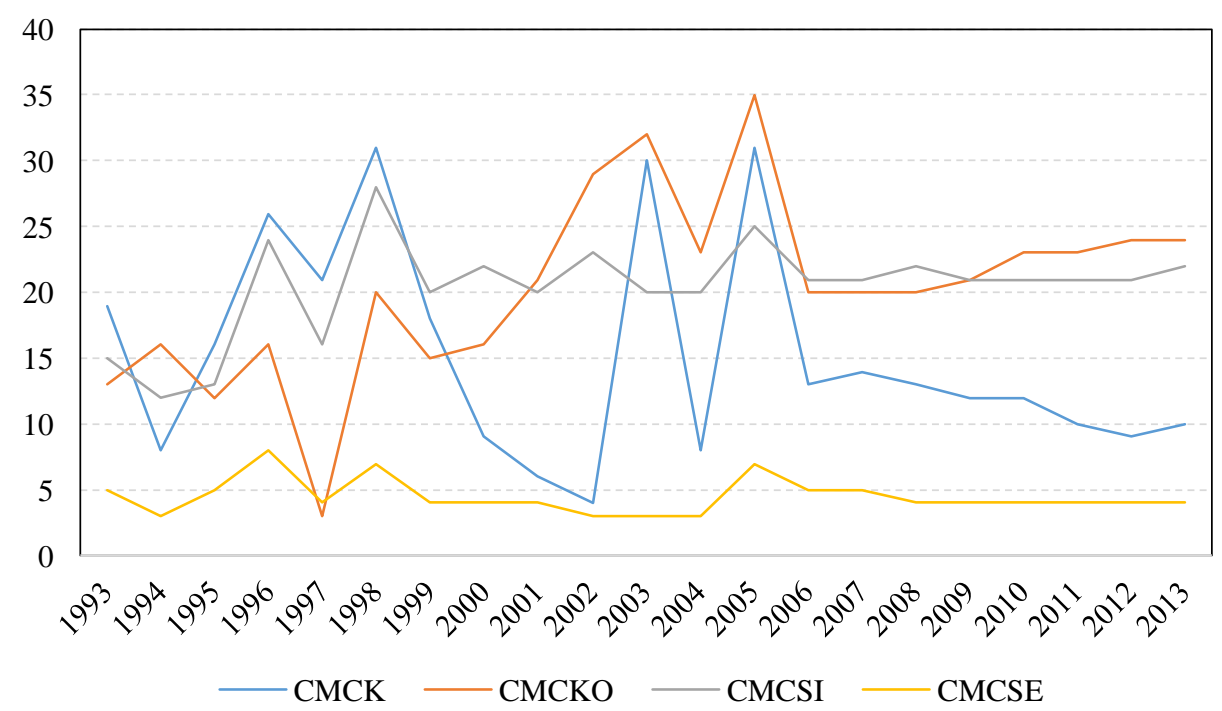

Source: Authors, 2019

Figure 2: Evolution of Commercial Margins of Collectors 


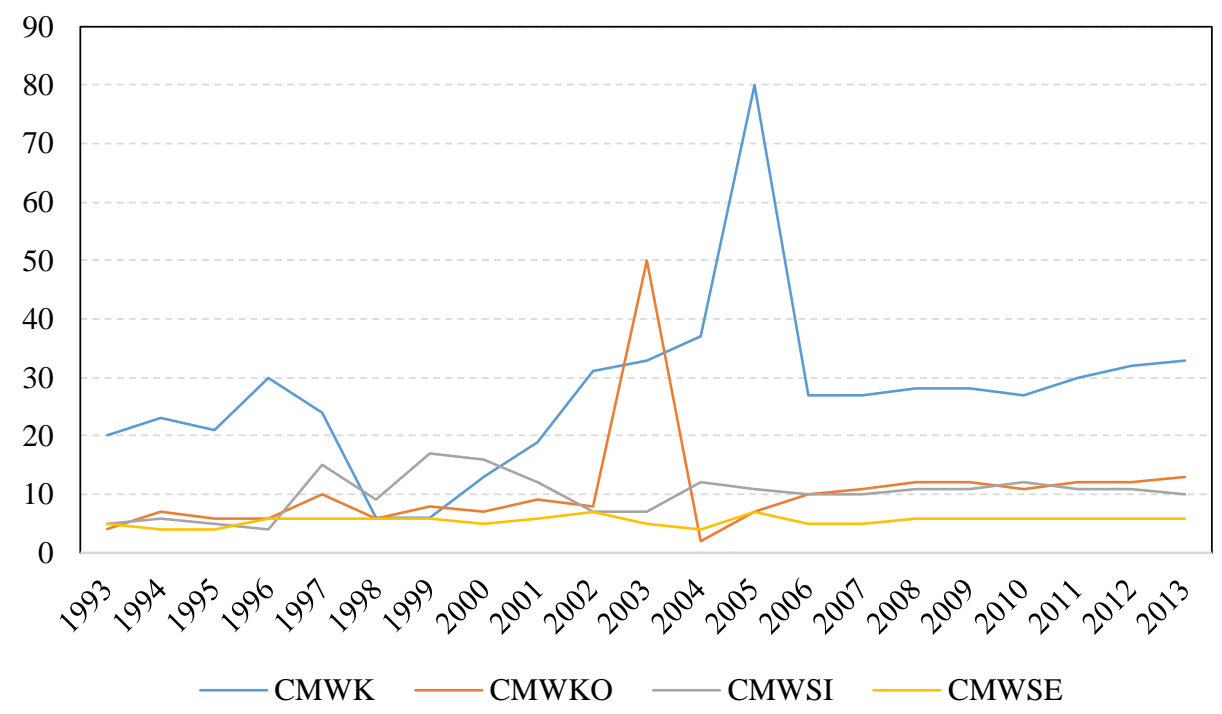

Source: Authors, 2019

Figure 3: Evolution of Commercial Margins of Wholesalers

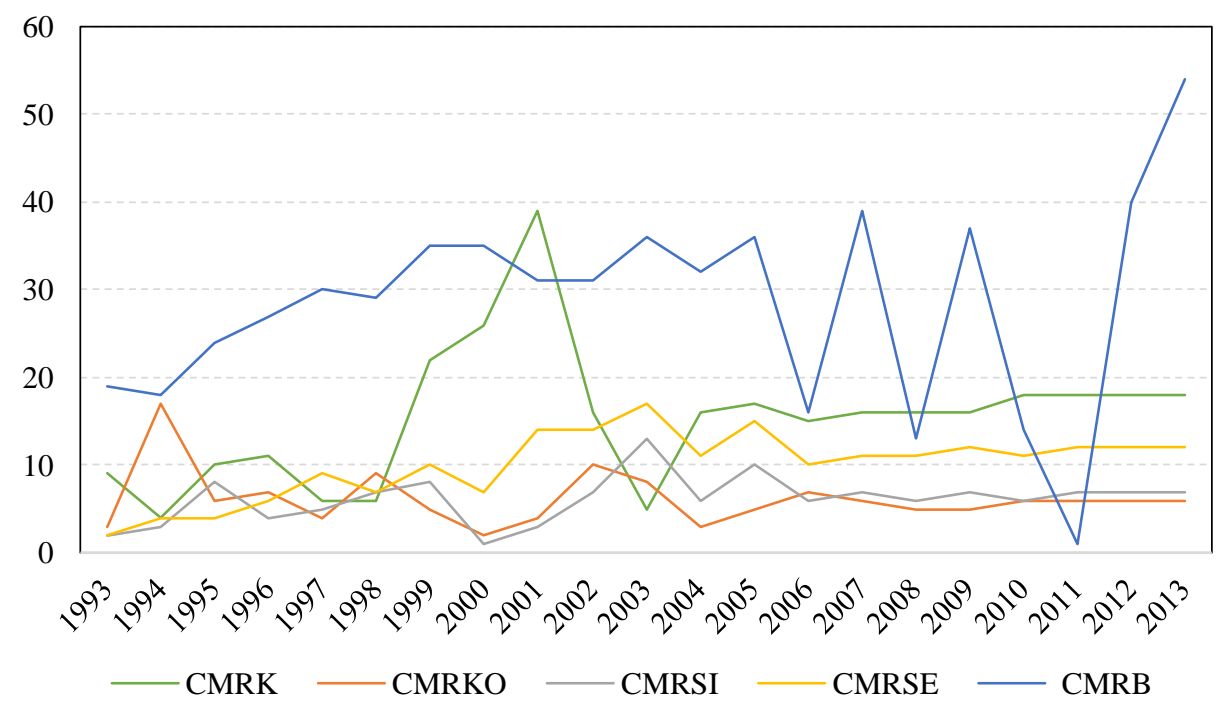

Source: Authors, 2019

Figure 4: Evolution of Commercial Margins of Retailers.

Consequently, we cannot also accept the hypothesis of asymmetrical cointegration between the pair market. If we take the F-statistic that tests the joint hypothesis $\rho_{1}=$ $\rho_{2}=0$, we find that this statistic is equal to 0.48 with a p-value of 0.48 , which is not significant. So, it mean that $\rho_{1}$ and $\rho_{2}$ are statistically equal. It is concluded that the price transmission effects of Ségou to Kayes are characterized by a symmetrical adjustment with a zero exogenous threshold. However, for Koulikoro-Segou relationship, the $\mathrm{t}-\max$ is 3.39 , and was greater than the critical value at the $1 \%$ threshold. For this relationship, we can not accept the hypothesis of asymmetrical cointegration between the Ségou and Koulikoro collection markets. Thus, the $\emptyset$-statistic of the same relation is 6.39 . This statistic is lower than the statistic read at the $1 \%$ threshold. Looking also at the probability of the joint statistic, we see that it is significant at $10 \%$. So the coefficients $\rho_{1}$ and $\rho_{2}$ is different. This then allows us to accept the hypothesis of asymmetrical cointegration between Koulikoro and Ségou' market. Regarding the Sikasso-Ségou relationship, the $\mathrm{t}$ - $\max$ is -5.29 . This value is less than the value read on the table of Enders and Siklos at the threshold at $1 \%$. Therefore, we can not accept the hypothesis of asymmetric non-cointegration (symmetrical cointegration) between the two market. The $\emptyset$-statistic analysis allowed us to reject the hypothesis of asymmetric non-cointegration between the market pair. Looking also at the probability of the joint statistic, we see that it is insignificant. So the coefficients $\rho_{1}=\rho_{2}=0$. Then, we can deduce the existence of a symmetrical cointegration relationship between the Sikasso and Ségou' market. In conclusion, there is a symmetrical cointegration 
relationship between Kayes-Ségou, Sikasso-Ségou pairs markets of zero exogenous at the collectors markets. Thus, the effects of positive shocks are transmitted in the same proportion as negative shocks. This means that, when a negative shock increases producer prices in Ségou so that the prices on the Sikasso, Koulikoro and Kayes collection markets will get above their long-run equilibrium levels, Sikasso, Kayes and Koulikoro' market will transmit in the same proportion in the case of a price decrease.

At the endogenous threshold, there is the existence of a threshold effect only for the Koulikoro-Ségou relationship where the $\rho_{i}(\mathrm{i}=1.2)$ are all negative and significant at the $5 \%$ threshold. The negative sign reflects the convergence of the estimated models. The response to positive shocks are twice as fast as the response to negative shocks as this is in contradiction at the previous studies which specifies that the negative shocks are twice as fast as the responses to negative shocks (Enders et Siklos, 2001; Chen et al., 2005; Abdulai, 2000; Sanogo and Maliki, 2008). On the other hand, negative shocks are more persistent than positive shocks. For example, following good rainfall in the Ségou region, which decreases colletor prices in Ségou, collectors in the Koulikoro areas will more rapidly transmit this price decreases on the Koulikoro producer markets until prices reach their long-term equilibrium levels.

The t-max calculated for the Koulikoro-Ségou relationship is -2.13 , which is higher than the value read on the table at the threshold of $1 \%$. Therefore, we cannot reject the null hypothesis of asymmetric non-cointegration between the market pair. The $\emptyset$-statistic value is 16.48 , which is greater than its read value at $1 \%$. We then reject the hypothesis of asymmetric non-cointegration in favor of the hypothesis of asymmetric cointegration between the market pair. This is concluded that the transmission effects of the shocks of the Ségou market to the Koulikoro market are characterized by an asymmetric adjustment with a threshold of -4.25. Thus, a shock in Ségou will lead to an asymmetric price response in Koulikoro only if this shock is much larger so that prices in Koulikoro are above or below their long-term equilibrium level plus the threshold.

At the wholesaler's side, the adjustment to negative shocks is much faster than the adjustment to positive shocks on Sikasso-Ségou market pairs at the zero exogenous threshold. At this threshold, positive shocks are much more persistent than negative shocks. On the other market despite that negativity of $\rho_{i}$, there are a symmetric prices transmission. The t-max calculated for the Kayes-Ségou, Koulikoro-Ségou and Sikasso-Ségou relationship are $-2.76,-2.35$ and -3.37 respectively. Comparing with their value read (-2.12) on the table at the threshold of $5 \%$, we note that they are all less than this value. In this case, we cannot reject the hypothesis of asymmetric cointegration between these market pairs at the exogenous zero threshold. The $\emptyset$-statistics for the same relationships are also $3.32,3.48$ and 6.61 respectively. They are all also less than the value read at the $1 \%$ threshold. Therefore, we cannot accept the hypothesis of asymmetric cointe gration between market pairs at the zero exogenous threshold. The statistic of the joint hypothesis for the Sikasso-Segou relation makes it possible to reject the symmetric transmission hypothesis in favor of the hypothesis asymmetric cointegration. From this result, we conclude that there is a symmetrical cointegration relationship between all market pairs except for the Sikasso-Segou relationship. We also note that the effects of positive shocks are equal to the effects of negative shocks. For example, following poor rainfall in the Ségou region, which pushes up wholesale prices in Ségou, wholesalers in the Sikasso areas will transmit this price increase on the Sikasso wholesale price at the same degree that a price decrease, until prices reach their long-term equilibrium levels.

With an endogenous threshold, the estimate also shows that the $\rho_{i}(\mathrm{i}=1.2)$ of the Kayes-Ségou and SikassoSégou relationship are all negative and significant. We find that the adjustment to positive shocks is very important than that to negative shocks for Sikasso-Ségou relationship but negative shocks are much more persistent than positive shocks. In the event of a good agricultural season in the Ségou region, lowering the wholesale price below its long-run equilibrium level, wholesalers in Sikasso will transmit this price decrease much more quickly to their own market until prices return to their long-run equilibrium level. Because the symmetrical transmission, the wholesalers of Kayes will transmit the price increases in the same proportion that the decreases. On the other hand, a bad crop season would cause a price increase above the long-term equilibrium level. By reasoning with the t-max statistic, we note that it is -2.99 for the Kayes-Ségou relationship and -3.22 for the Sikasso-Ségou relationship. These statistics are all below the tabulated critical value in Enders and Siklos (2001) at the critical $1 \%$ threshold. This means that we cannot reject the hypothesis of asymmetric cointegration at the $1 \%$ threshold. Referring to the $\emptyset$ statistic, we see that it is 4.85 for the Kayes-Ségou relationship and 3.87 for the SikassoSégou relationship. All of these statistics are less than the value read on the table at the $1 \%$ threshold. This allows us to reject the hypothesis of asymmetric cointegration between market pairs. The probability of the joint statistic $\rho_{1}=\rho_{2}=0$ is 0.102 for Kayes-Ségou and 0.08 for Sikasso-Ségou. At a threshold of $1 \%$, we cannot reject the hypothesis of asymmetrical cointegration between Sikasso-Segou. This leads us to admit that the market price transmission effects from Segou to the Sikasso wholesaler markets are characterized by an asymmetric adjustment with a threshold of -2.24. Thus, a shock in Ségou will lead to an asymmetric price response in Sikasso only if this shock is much larger so that prices in Sikasso are above or below their long-term equilibrium level plus the threshold.

The analysis of the relationship between the Bamako's retail market and Ségou's production, collection and wholesaler markets shows that all $\rho_{i}$ of all market pairs are negative and significant at the exogenous threshold zero. This allows us to admit the convergence of the estimated models. Indeed, the speed of adjustment to negative shocks is faster than that of positive shocks for retailer-Collector market. Nevertheless, the positive shocks are more persistent than negative shocks. The calculated $\emptyset$-statistics for producers, collectors and wholesalers market are respectively 4.86, 8.21 and 7.38. 
Apart from the collection market where there is asymmetrical cointegration, the transmission between the retail market and the other markets is symmetrical at the $1 \%$ threshold. The probability of the joint hypothesis $\rho_{1}=$ $\rho_{2}=0$ for all market pairs is insignificant. Therefore, we cannot accept the asymmetrical hypothesis between the market pair. We conclude the existence of the symmetrical cointegration between the market pair at the exogenous threshold null. At endogenous threshold, it is found that all $\rho_{i}$ are negative and significant only for the retailproducer market pair. Therefore, the estimated model is convergent. On the other hand, the response to positive shocks is roughly equal to the response to negative shocks. The $\varnothing$-statistic is 2.29 that suggests the existence of a nonasymmetric cointegration relationship between all the market pair with a threshold of -5.21 .

As a result, the econometric analysis first shows that all the series are integreted of null order. It also confirms the hypothesis of as ymmetrical cointegration between the Segou and Koulikoro collection' markets at the exogenous and endogenous threshold, and the Ségou and Sikasso wholesalers' market at the endogenous threshold. In the other markets, symmetrical transmission was observed between the pairs of markets. The symmetrical transmission is explain by the price competitiveness on the market. This mean that the wholesalers at Sikasso and Koulikoro can buying the product from another regions or countries and supply on their own market.

\section{SUMMARY AND CONCLUSION}

In this paper, the authors examined the role of intermediaries such as collectors, wholesalers, and retailers in the price transmission of millet in Mali's local millet market. To do so, they considered the most important cities, namely Bamako, Ségou, Kayes, Koulikoro and Sikasso. They used the Enders and Siklos (2001)'s Threshold Auto-Regressive method as well as monthly price data collected over the period 1993-2013 from the Agricultural Market Observatory, which contain the producer prices, the collector's prices, the wholesale prices and Bamako's retail prices of millet. The region of Segou is the leading producer of local millet in Mali while Bamako is more of a consumption region. At the exogenous threshold, we found also an asymmetrical transmission between Koulikoro and Ségou collectors' market' market. The result show that, collectors in Koulikoro quickly transmit price increases while they slowly transmit price decline. Strong evidence were found to suggest that, collectors in Koulikoro and wholesalers in Sikasso quickly transmit a decrease in millet prices to consumers while they slowly transmit the increase in prices to consumers even though the effect of prices increment are relatively larger than the effect of price decrease at endogenous threshold.

We found a non-asymmetric cointegration between Kayes-Ségou, and Sikasso-Ségou 'collectors market and between Sikasso and Ségou wholesalers' market when we chose a zero exogenous threshold. Regardless of the threshold chosen in retailers market, we found symmetric prices transmissions between all the markets pairs. The results indicate that intermediaries capture commercial margins leading to this asymmetric price transmission in the market of local millet. In order to reduce this asymmetric price transmission and to fight against poverty, the authors suggest that policymakers should consider introducing millet's price control in the local markets, especially when millet prices increase spontaneously.

\section{REFERENCES}

ABBASSI, A., TAMINI, L. D., \& GERVAIS, J. P. (2012). Do inventories have an impact on price transmission? Evidence from the Canadian chicken industry. Agribusiness, 28(2), 173-186. DOI: https://onlinelibrary.wiley.com/doi/abs/10.1002/agr.2129 $\underline{2}$

ABDULAI, A. (2000). Spatial price transmission and asymmetry in the Ghanaian maize market. Journal of development economics,63(2), 327-349. DOI: https://doi.org/10.1016/S0304-3878(00)00115-2

CARMAN, H. F., \& SEXTON, R. J. (2005). Supermarket fluid milk pricing practices in the Western United States. Agribusiness: An International Journal, 21 (4), 509-530. DOI: https://doi.org/10.1002/agr.20062

CHEN, L. H., FINNEY, M., \& LAI, K. S. (2005). A threshold cointegration analysis of asymmetric price transmission from crude oil to gasoline prices. Economics Letters, $\quad 89 \quad$ (2), 233-239. $\quad$ DOI: https://www.sciencedirect.com/science/article/pii/S01651 7650500217X

DIAKITE, L. (2006). Fonctionnement du marché céréalier au Mali. Une analyse néo-institutionnelle de son organisation et son efficacité temporelle et spatiale (Doctoral dissertation, Thèse de Doctorat de Sciences Economiques. Université de Ouagadougou (Burkina Faso)).

DIALLO, A., \& DIARRA, S. B. (2011). Etude sur la stratégie de commercialisation des céréales au Mali; Bamako. https://docplayer.fr/6511958-Rapportdiagnostic-etude-sur-la-strategie-de-commercialisationdes-cereales-au-mali-consultants.html

DIARRA, S., DIALLO, A., SOULE, B., \& STAATZ, J. (2011). Schéma de commercialisation des céréales au Mali. Ministère de l'Agriculture. Bamako.http://docplayer.fr/9250828-Schema-decommercialisation-des-cereales-au-mali.html

ENDERS, W., \& SIKLOS, P. L. (2001). Cointegration and threshold adjustment. Journal of Business \& Economic Statistics, 19(2), 166-176. DOI: https://doi.org/10.1198/073500101316970395

FIDAN, H., \& SAHINLI, M. A. (2010). Profit level and price fixing in hazelnut production. The Journal of Animal \& Plant Sciences, 20 (2), 117-122. DOI: https://www.researchgate.net/publication/266465875_Pr ofit_level_and_price fixing in hazelnut_production INSAT. (2017). Enquête Nationale Nutritionnelle et de Mortalité Rétrospective suivant la méthodologie SMART. Mali.https://fscluster.org/sites/default/files/documents/ra pport final_smart septembre 2018 mali.pdf

KINNUCAN, H. W., \& FORKER, O. D. (1987). Asymmetry in farm-retail price transmission for major dairy products. American journal of agricultural 
$\begin{array}{llll}\text { economics, } & 69 & (2), & 285-292 .\end{array}$ https://www.jstor.org/stable/1242278

LASS, D. A. (2005). Asymmetric response of retail milk prices in the northeast revisited. Agribusiness: An International Journal, 21(4), 493-508. DOI: https://doi.org/10.1002/agr.20061

LLOYD, T. A., MCCORRISTON, S., MORGAN, C. W., \& RAYNER, A. J. (2006). Food scares, market power and price transmission: the UK BSE crisis. European Review of Agricultural Economics, 33(2), 119-147. DOI: https://doi.org/10.1093/erae/jbl001

MACKINNON, J. G. (1990). Critical values for cointegration tests (pp. pp-267). San Diego: Department of Economics, University of California.http://qed.econ.queensu.ca/working_papers/pa pers/qed wp 1227.pdf

MEURIOT, V. (2012). Une analyse comparative de la transmission des prix pour l'orientation des politiques publiques : le cas du riz au Sénégal et au Mali (No.12 04).https://www.researchgate.net/publication/254427491

_UNE_ANALYSE_COMPARATIVE_DE_LA TRANS MISSION_DES_PRIX POUR_L'ORIENTATION_DES POLITIQUES_PUBLIQUES_LE_CAS_DU_RIZ_AU SENEGAL_ET_AU_MALI/stats

MEYER, J., \& VON CRAMON-TAUBADEL, S. (2004). Asymmetric price transmission: a survey. Journal of agricultural economics, 55(3), 581-611. DOI: https://doi.org/10.1111/j.1477-9552.2004.tb00116.x
MILLER, D. J., \& HAYENGA, M. L. (2001). Price cycles and asymmetric price transmission in the US pork market. American Journal of Agricultural Economics, 83(3), 551562. DOI: $\quad$ http://hdl.handle.net/10.1111/00029092.00177

OMA - Agricultural Market Observatory. (2013). Ministère de l'agriculture et de la sécurité alimentaire. Résultats définitifs de la campagne agricole et de la situation alimentaire et nitruuctionnelle. Ouagadougou. http://cns.bf/IMG/pdf/rapport_general_des_resultats_defi nitifs_2012_2013.pdf

SANOGO, I., \& MALIKI, A. M. (2008). Intégration des marchés du riz entre le Nepal et l'Inde: Application d'un modèle de cointégration à effet de seuil. https://docplayer.fr/20314680-Integration-des-marchesdu-riz-entre-le-nepal-et-l-inde-application-d-un-modelede-cointegration-a-effet-de-seuil.html

ŞAHINLI, M. A., \& FIDAN, H. (2012). Estimation of food demand in Turkey: method of an almost ideal demand system. Quality \& Quantity, 46(2), 653-663. DOI: https://link.springer.com/article/10.1007/s11135-010$\underline{9419-4}$ 